\title{
Food-borne Clostridium botulinum intoxication from mass produced foodstuffs in Europe
}

J Cowden (john.cowden@nhs.net)1

1. Health Protection Scotland, Glasgow, Scotland

Citation style for this article:

Cowden J. Food-borne Clostridium botulinum intoxication from mass produced foodstuffs in Europe.

Euro Surveill. 2011;16(49):pii=20033. Available online: http://www.eurosurveillance.org/ViewArticle.aspx?Articleld=20033

Article published on 8 December 2011

The incidence of botulism in the European Union (EU) in recent years is well described elsewhere [1]. In brief, in the EU between 2006 and 2008, 477 confirmed cases were notified: an average of 119 cases per year, with a range of 104 to 132 , and no discernable trend.

The surveillance of cases of botulism in the EU includes the three main forms of the disease but does not distinguish between them [2].

- Food-borne botulism is caused by the ingestion of toxin produced by organisms in an anaerobic environment. It usually results from inadequately sterilised domestically canned or bottled foods.

- Intestinal botulism is caused by the production in the gut of toxin by organisms which have been ingested and have proliferated. This form predominantly affects infants under a year old, often associated with the consumption of honey.

- Wound botulism is caused by the production of toxin by organisms introduced into wounds. This is often associated with dirty wounds, including those following injecting drug use.

Botulism is a severe disease that can be fatal in $5-10 \%$ of cases [3].

According to the European Centre for Disease Prevention and Control's (ECDC) Annual Epidemiological Report 2011, major causes of botulism in industrialised countries are contaminated and inadequately cooked foods, and ingestion by infants of spores in the environment [1].

Since 2009, Eurosurveillance has published only four reports of outbreaks of food-borne botulism in Europe $[4,5,6,7]$ and only three resulted from consumption of widely distributed, commercially produced foods $[4,5,6]$.

Despite only one of the four outbreaks being due to domestically prepared food [6], home-preserved food is generally acknowledged to be the major cause of botulism in those EU countries that have had most cases in recent years and outbreaks resulting from mass produced foods are rare.

Against this background, from September to November 2011, there were three outbreaks in three different countries in Europe. In the outbreaks which feature in this issue of Eurosurveillance, the vehicles of intoxication were demonstrated, on the basis of strong toxicological and descriptive epidemiological evidence, to have been widely distributed, commercially produced foods $[8,9,10]$.

These three outbreaks present intriguing differences and similarities.

- In two outbreaks, the Finnish and the Scottish, cases were confined to single households. In France cases occurred in two household clusters.

- In the French and Finnish outbreaks the vehicles included olives: olive tapenades in the French outbreak, and almond-stuffed olives in the Finnish. In the Scottish outbreak, the vehicle was korma sauce.

- In all three outbreaks the vehicle of intoxication was marketed in glass jars with screw-top lids.

- In the French and the Scottish outbreaks the food was produced and distributed within the country of origin. In the Finnish outbreak, the food was distributed internationally from another country, Italy.

- In the Finnish and the Scottish outbreaks the food was produced in industrialised units. In the French outbreak the producer was described as an "artisanal producer" although the tapenade was commercially produced and widely distributed.

- In the French and the Scottish outbreaks the toxin was type A. In the Finnish outbreak it was type B.

- In two outbreaks, the Finnish and the French, defects potentially explaining the contamination were identified. In the Finnish outbreak, seals in other jars from the same batch were found to have defects, although none was found to be contaminated. In the French outbreak an improper 
sterilisation process was identified. In the Scottish outbreak the food originated from a state-of-theart food-production facility where intensive investigation has yet to find any shortcomings, and no post-production event has been identified which could explain the contamination.

The number of cases in all three outbreaks was surprisingly low if a production fault is assumed to have affected the production of at least a whole batch of jars.

This is particularly true of the Scottish outbreak where only one household was affected, and which could be explained by the contamination of a single jar from a batch of 1,836 jars. Likewise, the Finnish outbreak affected a single household, and could be explained by only one contaminated jar of stuffed olives, despite the batch being part of a lot of 900 imported into Finland, and the product having been exported to many countries in Europe and beyond.

Only in the French outbreak does the contamination of more than one jar need to be hypothesised to explain the cases - and even here, contamination of only two jars could explain the cases. The size of the batch in the French outbreak was approximately 60 pots.

These outbreaks demonstrate that even modern industrialised production and distribution methods can occasionally allow contamination by botulinum toxin and prompt some important questions.

- How could a fault in production, distribution, retail, or domestic handling result in the contamination of a single item or so small a proportion to cause only a very limited number of cases from a large batch of product?

- If it is not possible to identify exactly where or how the contamination occurred, how can it be avoided in future?

- As risk can never be completely eliminated, do we have to accept that small outbreaks of diseases, even as deadly at botulism, and caused by mass produced foods are inevitable?

The first two questions relate to primary prevention, i.e. food safety. Ensuring safe food is the responsibility of food producers, and those who regulate them and enforce those regulations. These activities are beyond the scope of this editorial.

If, however, the answer to the last question is "yes", or even if it is "no" but it is accepted that the ideal is unachievable, then the role of secondary prevention is crucial. Secondary prevention in this context, i.e. the identification, investigation, and control of the outbreaks resulting from contaminated food, is the responsibility of local, national, and international public health and laboratory professionals.
In order for secondary prevention to be effective, the following actions must be carried out rapidly:

- identification of cases, which requires fit-for-purpose local and national clinical and laboratory surveillance;

- epidemiological investigation of the cases and their microbiological or toxicological confirmation, which requires an effective public health and clinical laboratory service;

- microbiological and toxicological investigation to confirm the vehicle, which requires a competent environmental laboratory service;

- dissemination of information about such cases, their occurrence, characteristics and exposures and the results of epidemiological and microbiological or toxicological investigations to others, which in case of the EU is facilitated through EU-wide coordinated alert systems, such as the Epidemic Intelligence Information System (EPIS) and Early Warning and Response System (EWRS);

- immediate control measures, which in these circumstances consist chiefly of the withdrawal of suspect foods, and the alerting of the public to the danger of any such foods which remain in their possession. This requires, not only systems such as the EU Rapid Alert System for Food and Feed (RASFF), but also efficient lines of communication outside the EU, for example with WHO and other national organisations such as the United States Centers for Disease Control and Prevention and, crucially, to the public.

All these systems appear to have worked well in the investigation and control of the three outbreaks reported in this issue. They can serve as a good example for politicians and policymakers who need to be aware of the necessity for the continuing development of such vital health protection activities, even in the current climate of constrained resources.

\section{References}

1. European Centre for Disease Prevention and Control. Annual Epidemiological Report 2011. Reporting on 2009 surveillance data and 2010 epidemic intelligence data. Stockholm: ECDC; 2011. Available from: http://ecdc.europa.eu/en/publications/ Publications/1111 SUR_Annual_Epidemiological_Report_on Communicable_Diseases_in_Europe.pdf)

2. European Commission Decision 2008/426/EC of 28 April 2008 amending Decision 2002/253/EC laying down case definitions for reporting communicable diseases to the Community network under Decision No 2119/98/EC of the European Parliament and of the Council (notified under document number C(2008) 1589) (Text with EEA relevance). Available from: http://eur-lex.europa.eu/Result.do? $\mathrm{T}_{1}=\mathrm{V}_{4} \& \mathrm{~T}_{2}=2008 \& \mathrm{~T}_{3}=$ 426\&RechType $=$ RECH_naturel\&Submit $=$ Search

3. Health Protection Agency (HPA). Infections A-Z. Botulism. London: HPA. [Accessed 8 Dec 2011]. Available from: http:// www.hpa.org.uk/Topics/InfectiousDiseases/InfectionsAZ/ Botulism/

4. King LA, Niskanen T, Junnikkala M, Moilanen E, Lindström $M$, Korkeala $\mathrm{H}$, et al. Botulism and hot-smoked whitefish: a family cluster of type E botulism in France, September 2009. Euro Surveill. 2009;14(45):pii=19394. Available from: http://www. eurosurveillance.org/ViewArticle.aspx?Articleld=19394

5. King LA, the French multidisciplinary outbreak investigation team. Two severe cases of botulism associated with 
industrially produced chicken enchiladas, France, August

2008. Euro Surveill. 2008;13(37):pii=18978. Available

from: http://www.eurosurveillance.org/ViewArticle.

aspx?Articleld $=18978$

6. Meusburger S, Reichert S, Heibl S, Nagl M, Karner F,

Schachinger I, et al. Outbreak of foodborne botulism linked to barbecue, Austria, 2006. Euro Surveill. 2006;11(50):pii=3097. Available from: http://www.eurosurveillance.org/ViewArticle. aspx?Articleld $=3097$

7. Lindström M, Vuorela $M$, Hinderink K, Korkeala H, Dahlsten E, Raahenmaa M, et al. Botulism associated with vacuumpacked smoked whitefish in Finland, June-July 2006. Euro Surveill. 2006;11(29):pii=3004. Available from: http://www. eurosurveillance.org/ViewArticle.aspx?Articleld=3004

8. Pingeon JM, Vanbockstael C, Popoff MR, King LA, Deschamps B, Pradel G, et al. Two outbreaks of botulism associated with consumption of green olive paste, France, September 2011. Euro Surveill. 2011;16(49):pii=20035. Available from: http:// www.eurosurveillance.org/ViewArticle.aspx?Articleld $=20035$

9. Jalava K, Selby K, Pihlajasaari A, Kolho E, Dahlsten E, Forss N, et al. Two cases of food-borne botulism in Finland caused by conserved olives, October 2011. Euro Surveill. 2011;16(49): pii=20034. Available from: http://www. eurosurveillance.org/ViewArticle.aspx?Articleld $=20034$

10. Browning LM, Prempeh $\mathrm{H}$, Little $\mathrm{C}$, Houston $\mathrm{C}$, Grant $\mathrm{K}$, Cowden JM, et al. An outbreak of food-borne botulism in Scotland, United Kingdom, November 2011. Euro Surveill. 2011;16(49): $\mathrm{pii}=20036$. Available from: http://www. eurosurveillance.org/ViewArticle.aspx?Articleld=20036 